(

- LA-UR -8i-2124

$$
\text { LCNF-8106.84--4.2 }
$$

TITLE: THEORETICAL EQUATIONS OF STATE FOR METALS

\title{
MASTER
}

\begin{abstract}
AUTHOR'S): Gerald I. Kerley
\end{abstract}
SUBMITTED TO: For proceedings of the 1981 APS Shock Wave Conferenc:
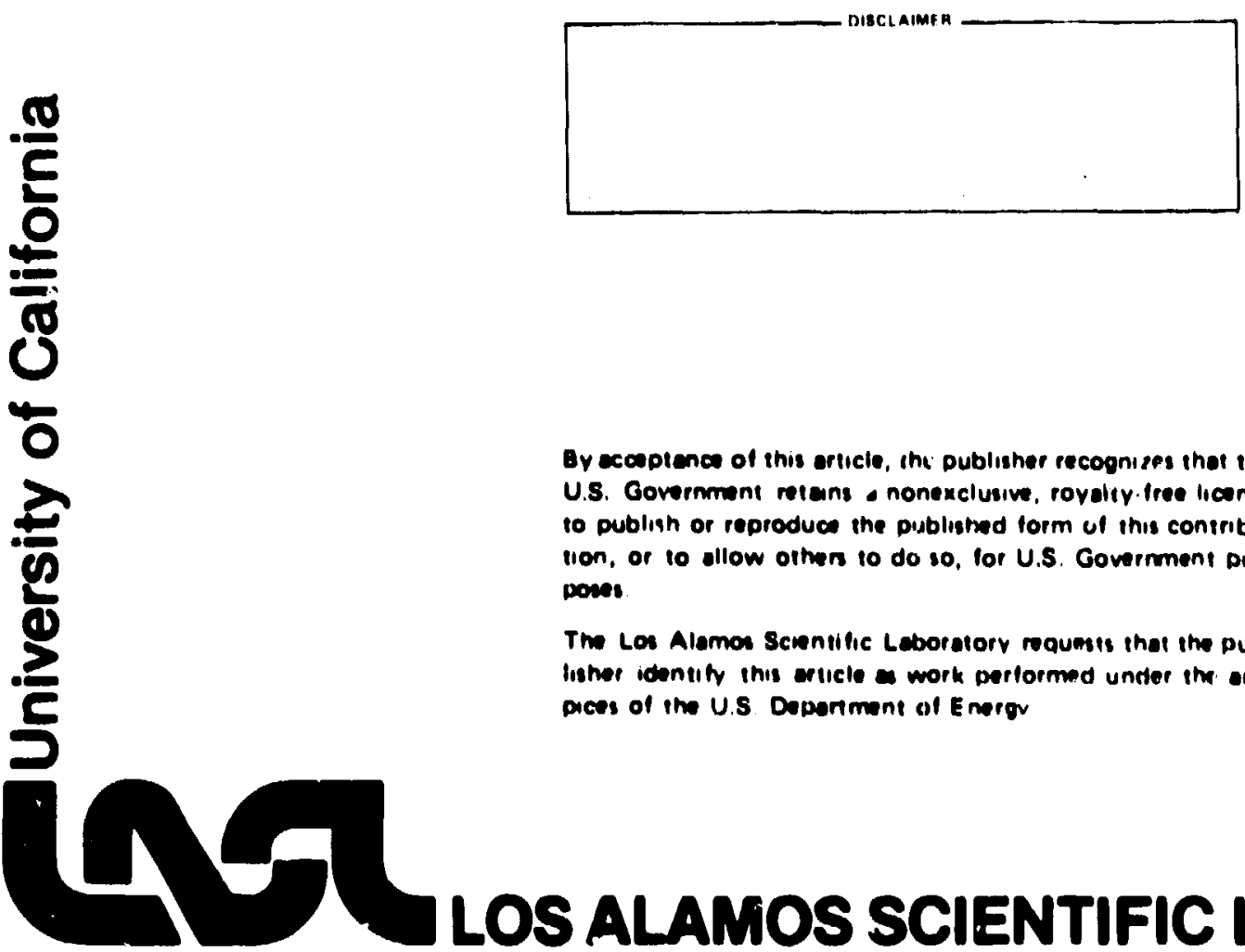

\begin{abstract}
By ecceptence of this erticit, the publisher recogni zes that the U.S. Government retens a nonexclusive, rovelif. Iree license to publish or reproduce the pidblistind form of this coniribu. llon, or 10 allow orters 10 do so, for U.S. Government pur powes.

The Lo Alemon Scientflic Leboratory requests that the puts lisher identity inis erticle a work perlormed under the ous press of the U.S Daperiment of Energr
\end{abstract}


THEORETICAL EQUATIONS OF STATE FOR METALS

G. I. Korley

Los Alamos National Laboratory, Los AlamoB, NM 87545

ABSTRACT

Equation of state (EOS) calculations for xenon, Iron, and beryllium are described and shown to give good agreement with shock wave experiments. The theory includes models for both solid and fluid phases, calculation of the melting curve, and effects of atomic shell structure on thermal electronic contributions to the EOS.

\section{DESCRIPTION OF THE MODELS}

Two conputer codes were ueed in our calculationa. The PANDA code ${ }^{1}$ computes the preseure, Internal energy, and Helmholtz froe energy, as functions of density and temperature, for both solid and fluid phases, the molting line is lxcated by matching the preseures and Gibbs free energies of the two phases as a function of tenperature. The INFERNO code of Ilbernen 2 computes the thermal electronic contributions to the EOS, which are input to PANDA.

The solld EOS consists of three terme. For exampie, the preseure is given by

$$
P_{g}(P, T)-P_{c}(D)+P_{1}(D, T)+P_{Q}(P, T) \text {. }
$$

where $\rho$ and $T$ are the denelty and temperature, respectively. $P$ is the sero kelvin leothern (cold curve), whlch w conetruct from fand theoretical calculations and experibentel data. $P_{1}$, the latidce vibrational term, is glven by the Dabye nolel. P is the thermal - loctronir. term, fron IATERNo, discuned below.

The fludd cos consiete of two terms. The preseure is written

$$
P_{f}(D, T)=P_{n}(D, T)+P_{e}(0, T)
$$

$P$ Includes contributions from the ground electronlc atete and from the notion of the nuclei. This term le conguted from hard ephere perturbation theory, uning the CRIs wodel. In this nodel, the unergy of a fluld atou in the cage formad by ite neighbors is deteralned from the cold curve of the eary to apacify the interatonic potentialo or any other parametere in ordar to calculate the fluld EOS. Contributions 1 ron the electronic and nuclear degrees of freedon are etrongly coupled, therefore, w do not epparate $P_{n}$ into a cold ourve and a thermal term a do for the colja.

- supported by the U.8. Department of Energy, Office of Baic Energy sciences 
The INFERNo model of Iiberman ${ }^{2}$ is used to compute the thermai electronic contributions to the EOS for both solid and fluid phases. In this theory, the Dirac equation ir solved to obtain wave functlons and thermodynamic properties for an average atom, as a functIon of both density and temperature. An important feature of the theory is that it includes effects due to atomic shell structure, that are smearged out in simpler models such as Thomas-Fermi-Dirac (TFD) theory.

XENON

Like all matexials, xenon is expected to become metalilic at high densities. Zero temperature band theo etical calculations of Ross and McMahan ${ }^{5}$ predict the energy gap between the filled $5 p$ band and the empty conduction band to close at a density of $12 \mathrm{~g} / \mathrm{cc}$. In shock wave experiments, where there is thermal electronic excitation, effects due to this insulatormetal transition can be observed at lower densities.

The thermal electronic pressure calculated using the INFERNO model is shown in $1 \mathrm{~g} .1$. At densities in the range $2-10 \mathrm{~g} / \mathrm{cc}$,

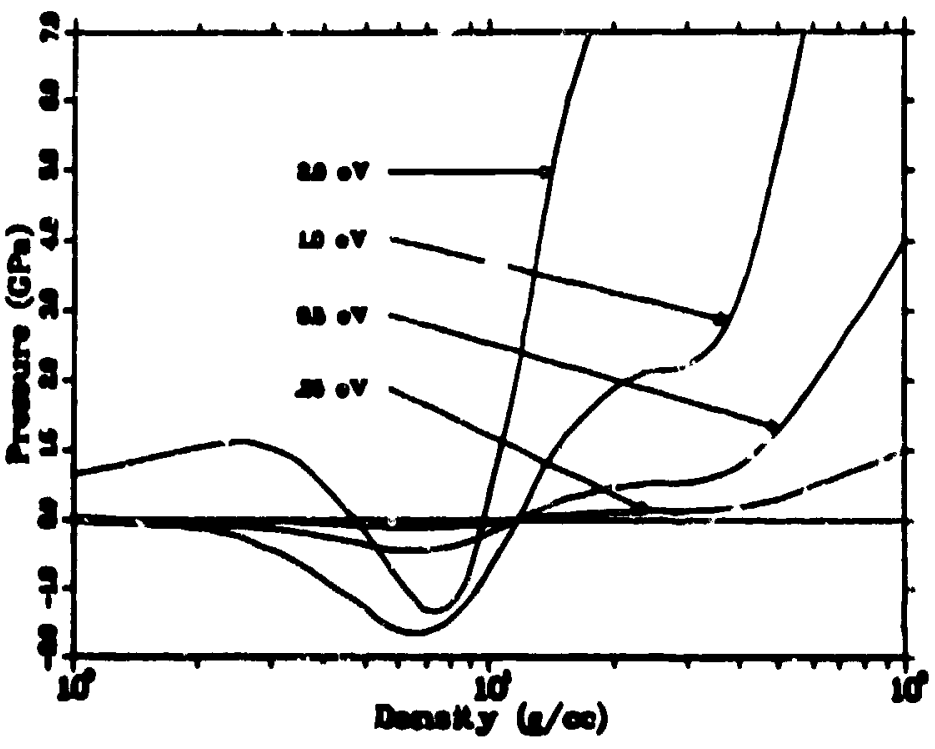

Fig. 1. Thermal electronle preseure for xenon, as a function of density, at several temperatures. narrowing of the band gap allows increased lectronic excitation and also results in a negative contribution to the fressuxe. This result agrees with Ross's mudel ${ }_{5}$ for the raxe gases.

In this work, the cold curve was taken from the band calculations of Ross and McMahan, 5 shown as circles in Fig. 2. This result, togother with the CRIs model and the INFERNo model, completely define $t \cdot$ Iluid zOs a priort. our predictions of the Higoniot are compared with experiment in

F1g. 2. If no slectronlc excltation is allowed, the calculations deriate sharply from exporiment at high pressures. When the TrD model is used to describe the electronic excitations, the results are better but etill not entiafactary. Calculation using the

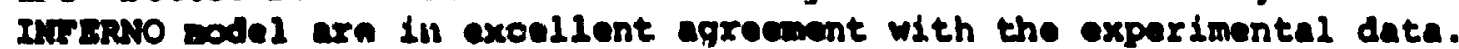
INRERNO predicte matallisation to occur at about $10 \mathrm{~g} / \mathrm{cc}$, in fair agroament with the band theoretical calculationa. 


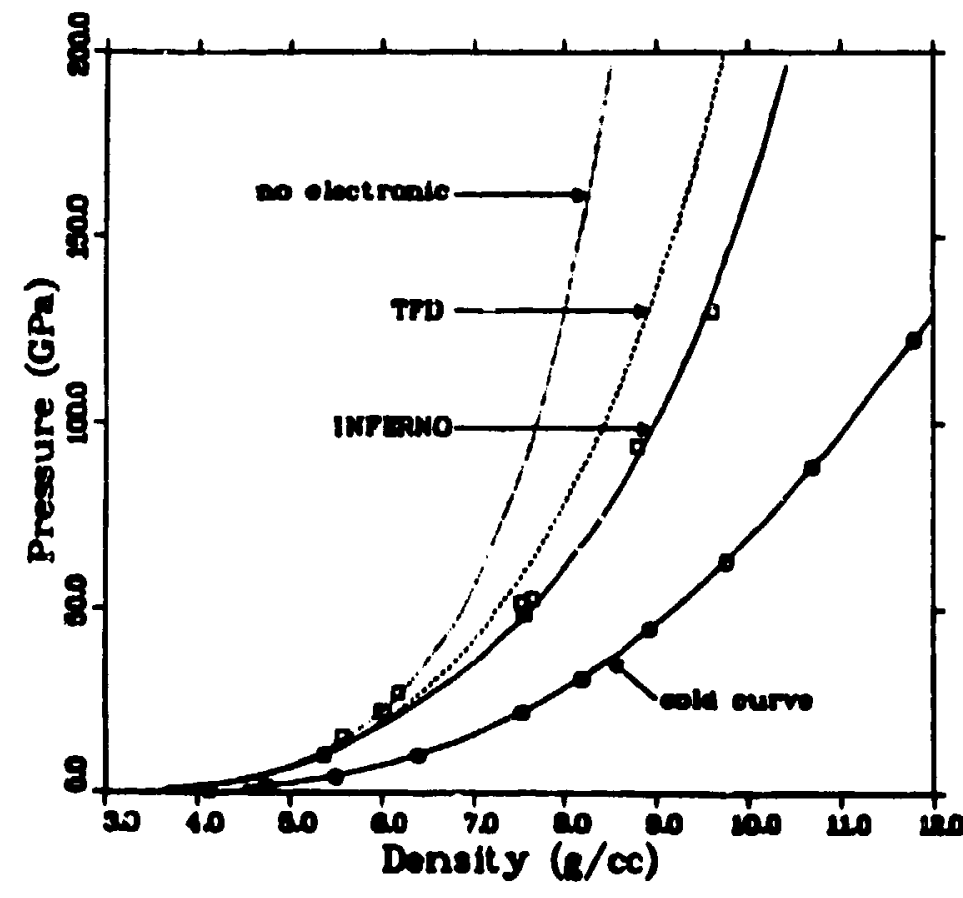

Fig. 2. Cold curve and Hugonini for xenon.

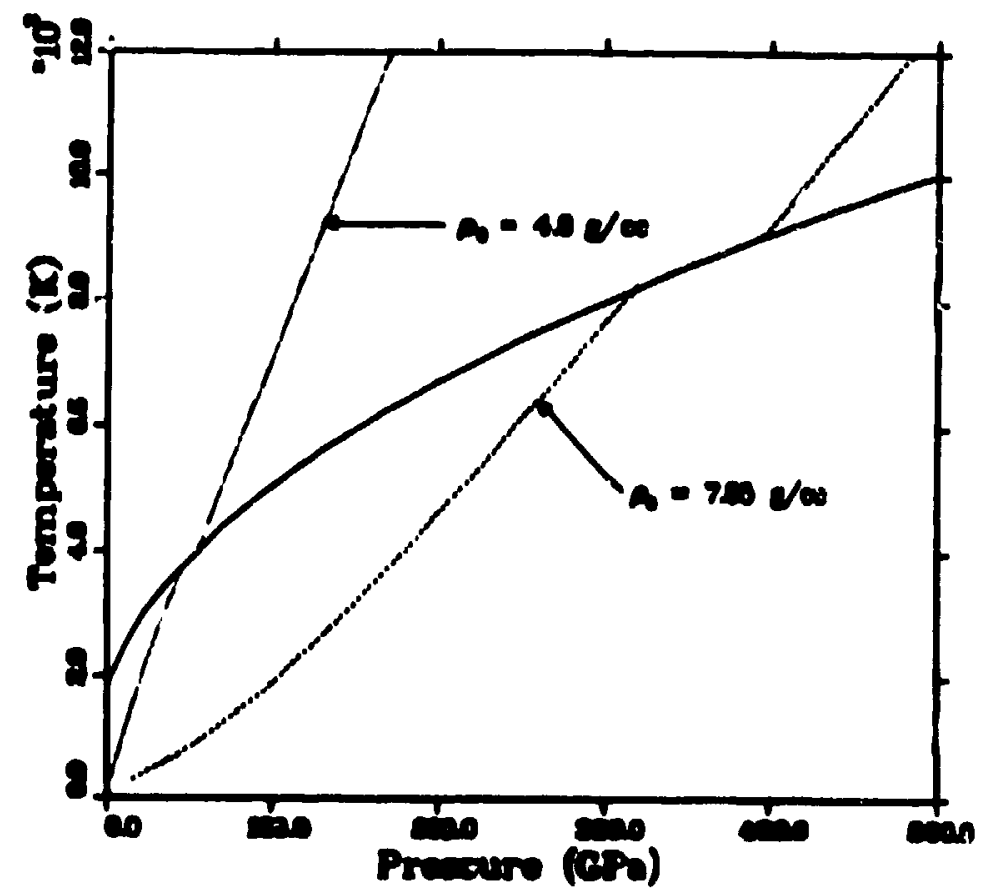

F1g. 3. Iron melting curve and Hugonioto Lor two initial denaitiea.
IRON

Application of the theory to Iron is corplicated by the exi.stence of several solid phases. In this work, we considered only the close packed $\varepsilon$-phase, which is stable at pressures above 13 GPa. The cold curve was taken from the static high pressure experimen:al dgta of Mao ard Bell. Our theoretical melting curve for iron 18 shown in Fig. 3. In this calculation, we forced agreement with the experimental mejting point at zero presoure by subtracting an empiricallydetermined constant from the free energy of che flusd. (Thjs correcticn was about 4t of the oolid bindIng energy.) Calculated Hugonlots for two initiul densities axe also shown in F1g. 3. Alpha-phase Iron, having a denalty of $7.85 \mathrm{~g} / \mathrm{cc}$, is predicted to begin melting at about 300 GPa, In Ealr agreement: with the velue of 250 Gra obtained by Brows and Meiquen. Porous a-phase Iron, having - denatey of $4.8 \mathrm{~g} / \mathrm{sc}$. 10 predicted to bagin melting at 45 GPa. 
Shock velocity vs. particle velocity curves for iron of various initial densities are shown in rig. 4. Agreement between the theory

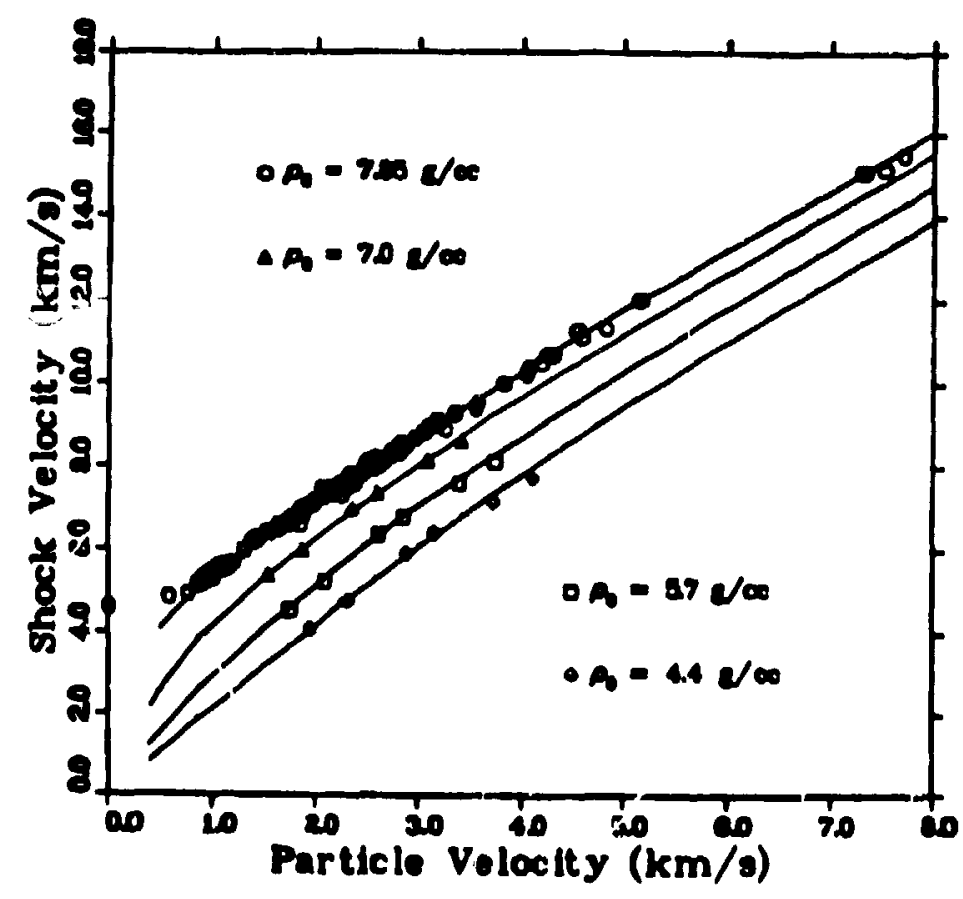

Fig. 4. Shock velucity vo. particle velocity for iron at several injtlal densities.

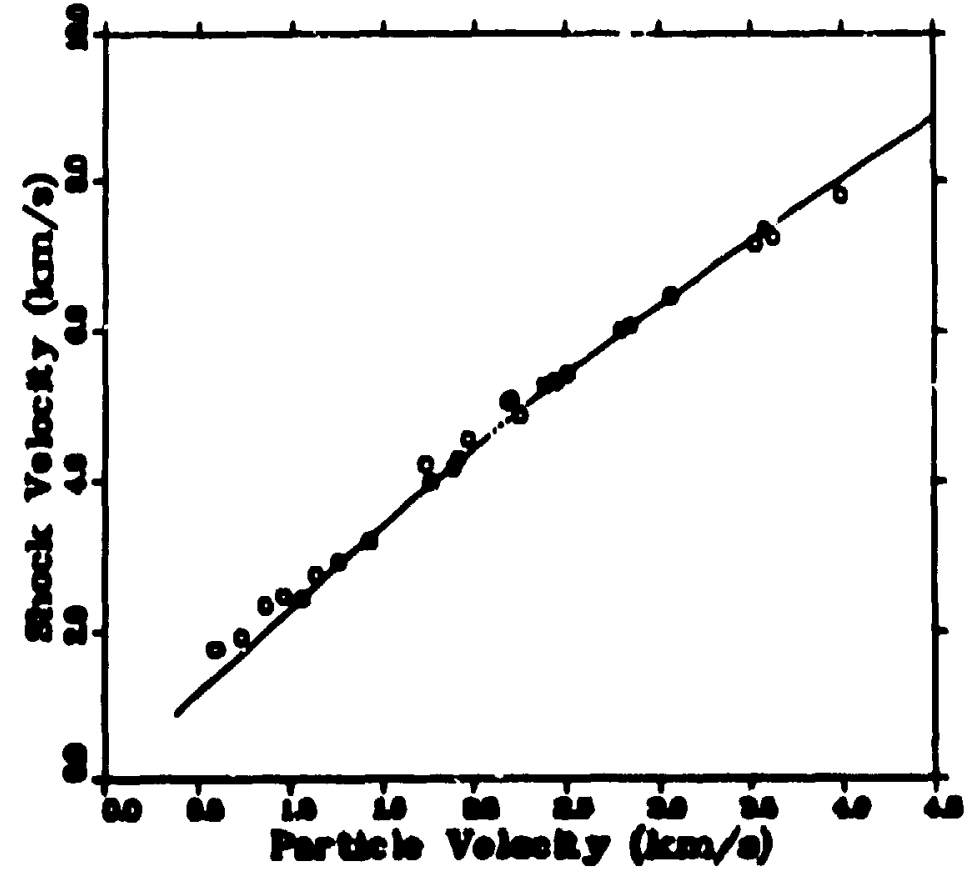

F1g. 5. Mugorilot for porous iron having an Intelal density of $4.8 \mathrm{~g} / \mathrm{cc}$. and the experimental

data $8-10$ is very good for both solid and flutd phases over the entire range, which extends to $1000 \mathrm{GPa}$. More datail can be seen in Fig. 5, showipg the ahock data 8,10 for an initial density of $4.8 \mathrm{~g} / \mathrm{cc}$. In the calculated Hugoniot, the mixed phase region is shown by a dashed line. Agreement with the experimental data 18 excellent except at the lowest pressures, for which the shocked state is in the $\alpha$-phase.

\section{BERYLLIUM}

The cold curve for beryllium wa: taken from the band theoretical calcutetione of Perrot, shown as circles in Fig. 6. The solld EOS is fairly mensitive to the form of: the Grïnoleen paraniater. We ueed the exprcsaton

$$
\gamma=1.3 / p+2 / 3
$$

which agrees with both thermodymanic data and real's shock you meavurements 12 to wthin experimental error. 


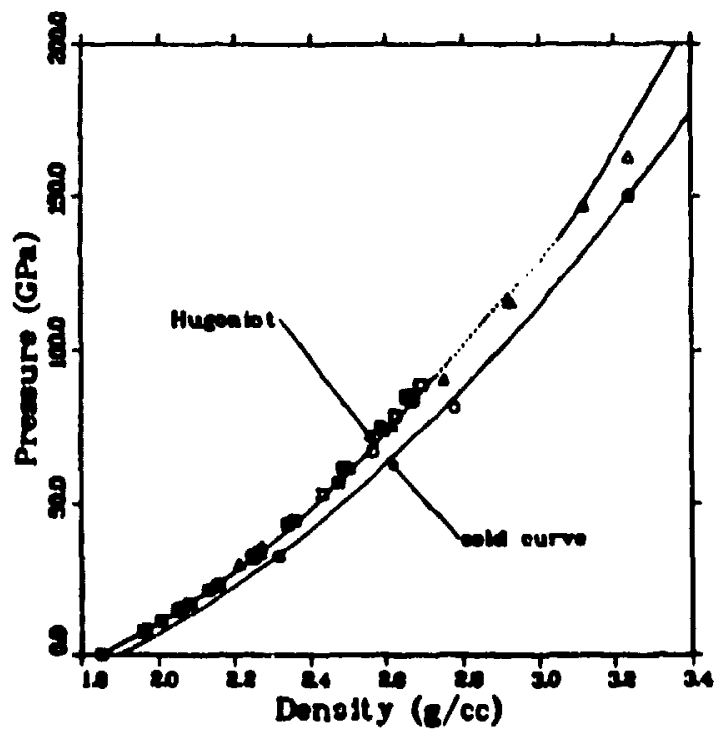

Fig. 6. Cold curve and Hugoniot for beryllium.
The calculated melting point at zero pressure is 1545 $K$, in good agreement with experiment. The theoretical melting curve has a mall negative slope over the pressure range 10-160 GPa, and melting is predicted to begin at about 90 GPa, under shock loading.

The theoretical Hugopjof ${ }_{3}$ is compared with experiment

in Fig. 6. The mixed phase region is depicted by a dashed line. Our theory predicts a significant softening of the Hugoniot. due to melting. These calculations are in very good agreement with the data of rsbell, et. al., I3 shown by triangles. New measurements in this high pressure region would be useful.

\section{REFERENCES}

1. G. I. Kerley, "Users Manual for PANDA: A Computer Code for Calculating Equations of State," Los Alamos National

Laboratory report LA-8B33-M (1981).

2. D. A. L1barman, Phys, Rev. B20, 4891 (1979).

3. G. I. Kerley, J. Chem. Phys. 73,469 (1980), 73, 478 (1980).

4. R. D. Cowan and J. Ashkin, Phys. Rev. 10:, 144 (1957).

5. M. Rose and A. K. Mcmahan, Phys. Rev. B21, 1658 (1980).

6. W. Nel118, M. van Thie1, A. C. Mitche11, and M. Ross, "The Equation of State of $D_{2}$ and $X e$ in the Megabar Region," presented at the Elghth Internatfonal Thermophysical Properties Conference, National Bureau of Stendarde, Wash. D.C., 1981.

7. H. K. Mao and P. M. Bell, J. Geophys. Res. 84, 4533 (1977).

8. J. M. Brown, and R. G. Mequeen, J. Geophys. Res., t.o be publ1ahaci.

9. L. Y. Al'tahuler, N. N. Kalitkin, L. V. Kuz'mina, and B. S. Chakin, Sov. Phys. JETP 45, 167 (1977).

10. 8. P. Marsh, LASL Shock Hugoniot Data (University of California, Berkelej, $198 \overline{\text { J. }}$

11. F. Perrot, Phya. Kev. B21, 326\% (1980).

12. T. Neal, "Determination of the Grüneifen $Y$ ior Beryllium at 1.2 to 1.9 Time sturdard Density," In high Pressure soience and Technology. 8xxth AImpry confexence, odited by K. D. Timingus and M. S. Barber (Plenum Prese, NY, 1979) Pg. 80.

13. W. M. Isbel1. F. H. ShIpman, and A. H. Jones, "Hugoniot Equation of state of Eleven Elemente to Five Mara," Materlals Scienco Laboratory report MSL-68--3. 